\title{
The Frequency of Fibromyalgia in Migraine Patients
}

\author{
Ali Younis*(D), Yahya Qasem (D) \\ Department of Medicine, College of Medicine, University of Mosul, Mosul, Iraq
}

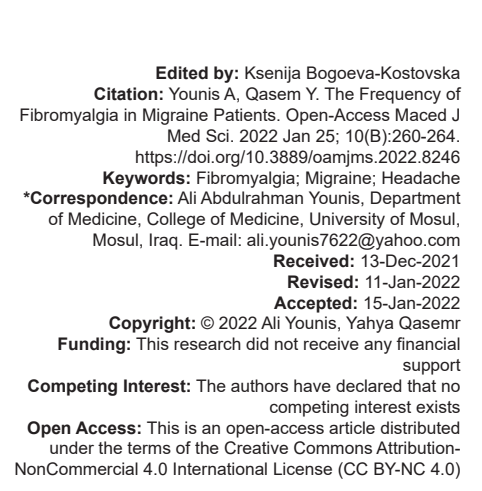

\section{Introduction}

Fibromyalgia (FM) is a prevalent disorder marked by chronic diffuse pain, often accompanied by tenderness, fatigue, mood changes, sleep disturbances, and other somatic problems [1], [2]. Comorbid FM has been reported in patients with migraines in several studies [3], [4], [5], [6]. The strike of FM pain was demonstrated to be triggered by environmental factors, including stress and infections. Similarly, migraines are triggered by environmental factors (e.g., stress, strong light, or noise); therefore, their association and coexistence are potentially possible [2]. "Central sensitization" may be involved in both FM and migraine [7]. Pain amplification at a central level and its persistence despite the termination of the primary cause may explain the comorbidity of both conditions. One possible explanation is that pain modulating pathways are faulty in these disorders. Decreased adaptation to painful stimuli may lead to an increase in noxious input in the cortex, promoting central sensitization. This phenomenon has been found in migraine and FM patients [8]. FM is a devastating illness that, when combined with migraine, can rise morbidity [3], [4]. Comorbidity is relevant in migraine from various points of view: Comorbid disorders can make diagnosis more difficult; one disease can alert physicians of other diseases, and one treatment can be taken to treat both conditions. The etiology of migraine can be elucidated by looking at the comorbidity of disorders [9]. Physicians dealing with migraine patients should be aware of the connection between migraine and FM. This study aimed to estimate the frequency of FM in migraine patients and to evaluate the characteristics of migraine patients with comorbid FM.

\section{Patients and Methods}

\section{Study setting and design}

This case-control study was enrolled 100 consecutive patients with migraine in the Neurology Unit, Department of Medicine in Ibn Sina Teaching Hospital, between March and November 2020. For comparative purposes, a total of 100 healthy control individuals matched for age and sex were selected. They had no migraine or any type of headache.

\section{Ethics approval and patients informed consents}

The study was done in conformity with the Declaration of Helsinki's principles, and all participants supplied written informed consent before 
the study's start. The study protocol was approved by the Department of Medicine, College of Medicine, University of Mosul (approval date: September 17, 2020, no: MDESC9-2).

\section{Eligibility}

The diagnosis of migraine was confirmed based on the International Classification of Headache Disorders, $3^{\text {rd }}$ edition (ICHD-3) by a neurologist [10]. Patients with other types of headaches, neurological illnesses, or other recognized purposes of widespread pain, such as endocrine, rheumatic, or systemic problems, were omitted from the present study.

\section{Data collection}

Sociodemographic features (age, gender, body mass index, marital status, employment position, and education) and headache characteristics (headache intensity, frequency, migraine type, and duration) were recorded. The diagnosis of FM was done according to the 2011 modification of the "2010 American College of Rheumatology preliminary diagnostic criteria for FM" by one rheumatologist [11]

\section{Assessment and evaluation}

The "Headache Impact Test-6 (HIT-6)" is an endorsed questionnaire used to quantify the disruption in the daily life of the patient caused by migraine (range: 36-78). This questionnaire includes six domains that assess how often recent headaches resulted in severe pain, how often they limit the ability to perform regular daily activities, and how often they led to the need to lay down, headache-related tiredness, irritability, or difficulty concentrating [12].

The "Migraine Disability Assessment Scale (MIDAS)" is a quick and accurate headache-specific measure for calculating headache-related disability. In five questions, the impact of headaches on everyday activities over the previous 3 months is studied. Items 1 and 2 look into the number of days absent from work comeuppance to a headache, as well as the number of days when the mass productiveness is cut in half or more. The identical questions about domestic work are asked in Items 3 and 4 . Item 5 inquires about days spent participating in recreational, social, and family events that were missed. A higher score suggests that the disability is more severe [13].

The Patient Health Questionnaire-9 "(PHQ-9)" is an endorsed depression screening tool. It includes nine assertions of depressive symptoms that are assessed on a scale of 0-3 (never, a few days, more than half the days, and virtually every day) over the preceding 2 weeks [14].
Headache intensity was evaluated on a numerical rating scale of $0-10$, with 0 denoting "no pain" and 10 denoting "the worst pain imaginable."

\section{Statistical analysis}

"Statistical Package for the Social Sciences" version 23 was used for statistical analysis. The mean and standard deviation of continuous variables were calculated. For the comparison of qualitative data, the Chi-square test was utilized. The differences between the two means were calculated using the "Student's t-test." Statistical significance was defined as $p<0.05$.

\section{Results}

One hundred participants with migraine, 28 males $(28 \%)$ and 72 females $(72 \%)$, their mean age $30.76 \pm 9.9$ years, and 100 healthy control group, 30 males (30\%) and 70 females $(70 \%)$, their mean age was $32.4 \pm 7.30$ years, were included in this study. Gender distribution among patients and control groups was shown in Figure 1. The age and sex of the studied groups were matched, with no significant statistical difference between them $(p>0.05)$.

The frequency of "FM" in 100 participants with migraine was $27 \%$ compared to $5 \%$ in 100 healthy individuals $(p=0.00002)$ intimating a statistically significant variation between the studied groups, as shown in Table 1.

Table 1: Comparison of FM between patients with migraine and control groups

\begin{tabular}{llll}
\hline Fibromyalgia status & $\begin{array}{l}\text { Cases (migraine) } \\
\mathrm{n}=100\end{array}$ & $\begin{array}{l}\text { Controls (no migraine) } \\
\mathrm{n}=100\end{array}$ & $\mathrm{p}$-value \\
\hline Fibromyalgia, $\mathrm{n}(\%)$ & $27(27)$ & $5(5)$ & 0.00002 \\
No fibromyalgia, $\mathrm{n}(\%)$ & $73(73)$ & $95(95)$ & \\
\hline
\end{tabular}
FM: Fibromyalgia

Table 2 displays the sociodemographic features of "migraine" patients with and without "FM." Participants with coexisting "migraine" and FM had a substantially greater mean age and percentage of female than migraine patients without FM (39.96 \pm 7.67 vs. $27.36 \pm 8.39, p=0.0001 ; 88.9 \%$ vs. $65.75 \%$, $p=0.022)$. Other sociodemographic features, such as body mass index, marital status, educational status, and employment position, did not show a substantial difference between the studied groups ( $p>0.05$ for all).

Table 2: Sociodemographic features of "migraine" patients with and without "FM"

\begin{tabular}{llll}
\hline Variable & $\begin{array}{l}\text { Migraine patients } \\
\text { with } \mathrm{FM} \mathrm{n}=27\end{array}$ & $\begin{array}{l}\text { Migraine patients } \\
\text { without } \mathrm{FM} \mathrm{n}=73\end{array}$ & p-value \\
\hline Mean age, years & $39.96 \pm 7.67$ & $27.36 \pm 8.39$ & 0.0001 \\
Gender (F/M), $\mathrm{n}(\%)$ & $24 / 3(88.9 / 11.1)$ & $48 / 25(65.75 / 34.25)$ & 0.022 \\
Body mass index $\left(\mathrm{kg} / \mathrm{m}^{2}\right)$ & $27.3 \pm 5.4$ & $25.9 \pm 4.2$ & 0.175 \\
Married, $\mathrm{n}(\%)$ & $20(74.1)$ & $54(74)$ & 0.99 \\
Employed, $\mathrm{n}(\%)$ & $8(29.6)$ & $24(32.9)$ & 0.76 \\
Education, years & $8 \pm 3.6$ & $9.4 \pm 4.2$ & 0.128 \\
\hline FM: Fibromyalgia & & &
\end{tabular}


Headache characteristics among "migraine" participants with and without FM are demonstrated in Table 3. FM was found to be more common in patients without aura ( $p=0.017)$, whereas there was no difference between them concerning disease duration and the presence of menstrual migraine. Patients with comorbid FM had greater headache frequency $(p=0.000)$, headache intensity $(p=0.007)$, and higher scores on the HIT-6 ( $p=0.0001)$, MIDAS $(p=0.0167)$, and PHQ-9 ( $p=0.001)$.

Table 3: Headache characteristics among migraine patients with and without FM

\begin{tabular}{llll}
\hline Variable & $\begin{array}{l}\text { Migraine patients } \\
\text { with FM } \mathrm{n}=27\end{array}$ & $\begin{array}{l}\text { Migraine patients } \\
\text { without FM } \mathrm{n}=73\end{array}$ & p-value \\
\hline Duration of migraine, years & $7.3 \pm 6.4$ & $6.5 \pm 5.3$ & 0.53 \\
Migraine frequency (per month) & $9.8 \pm 6.6$ & $5.6 \pm 4.1$ & 0.0002 \\
Headache intensity & $8 \pm 1.5$ & $7.2 \pm 1.2$ & 0.007 \\
Migraine with aura, $\mathrm{n}(\%)$ & $3(11.1)$ & $26(35.6)$ & 0.017 \\
Menstrual migraine & $7(33.3)$ & $12(23.5)$ & 0.391 \\
HIT-6 & $64.7 \pm 5.1$ & $57.4 \pm 7.3$ & 0.0001 \\
MIDAS & $29.5 \pm 12.6$ & $21.8 \pm 14.5$ & 0.0167 \\
PHQ-9 & $15.4 \pm 5.6$ & $10.8 \pm 6.4$ & 0.001 \\
\hline FM: Fibromyalgia, HIT-6: Headache & Impact Test-6, MIDAS: & Migraine Disability Assessment Scale,
\end{tabular}

PHQ-9: Patient Health Questionnaire-9

\section{Discussion}

The outcome of the present study revealed that FMwas detectedin $27 \%$ ofmigraine patients incomparison to $5 \%$ of healthy individuals which indicate a statistical relation betwixt the two conditions $(p=0.00002)$. This finding agreed with the previous studies which showed a high frequency of $\mathrm{FM}$ in migraine patients, ranging between 10 and 35.6\% [3], [4], [5], [6], [15]. The apparent variation in FM frequency between studies could be attributable to the use of different FM classification criteria or inconsistencies in their application. The "FM classification criteria" are not without limitations, and the "ACR" has established clinical criteria that do not include examination for tender spots, but it gives a metric for assessing the intensity of symptoms that are common in FM. These new criteria would be easier to use and would make diagnosing FM distress much easier.

Because the study was conducted in a hospital-based neurology unit, the high frequency of FM among migraine patients may not be reflective of migraine distribution in the general population. As evidenced by high headache intensity, "MIDAS," and "HIT-6" scores, the sample under investigation had more severe symptoms of migraines than other groups of patients. Community-based researches are needed to determine the link between these illnesses in the general population.

This frequent association of migraine with FM could be possibly attributed to a common pathophysiologic basis. As a common mechanism for both FM and migraine, hypothalamic neuroendocrine dysfunction has been suggested [16]. The central pain transmission circuits signaling through pain neurons also have been anticipated as a pathway shared by both conditions [17]. Low levels of magnesium can worsen FM symptoms and are also implicated in migraines [18].

The instant study demonstrated that patients with migraine and comorbid FM had the tendency to be older, and most were female. Our findings were in agreement with the previous studies [4], [8], [9]. It is known that the frequency of "FM" rises with age and that both migraine and FM predominate in females. However, gender variations in these diseases are not entirely understood, but they are most likely the consequence of a complex interplay between gonadal hormones, brain processes, and pain processing [19], [20], [21].

Regarding the relationship between FM and the presence of aura, FM was found to be more common among patients without aura. This inspection is supported by few other studies [3], [15]. In a paper published by Ifergan et al., FM was identified in approximately all aura-free migraine patients [3]. FM comorbidity was not observed in patients who presented with aura strikes, according to de Tomasso et al. [8]. However, this contradicts with Beyazal et al. who have stated that aura is more prevalent when migraine coexists with FM than those with FM-free migraine patients [9]. A possible explanation may be that in the studies with a significant association between aura and FM, other factors such as frequency of migraine headache might have influenced the analyzes.

In our study, the frequency of migraine episodes was statistically greater in individual with FM compared to those without "FM." In a study done by "de Tommaso et al.," the rate of headache was stated as one of the major discrimination variables for FM distress [22]. In a subsequent study, FM was more prevalent betwixt migraine patients who testified more prevailing migraine attacks [5]. Increased migraine frequency increases pain intensity in somatic areas beyond the cranium, and patients may be predisposed to FM [23]. In our study, patients with comorbid FM had significantly greater headache intensity, and higher grades on the HIT-6, and MIDAS. This study backs up prior findings that people with FM and migraine had more severe headaches and headache-related impairment than those who simply have migraines [4], [6].

Scores on PHQ-9 were significantly greater in patients with concomitant FM. Our finding was in agreement with the previous studies which show increased depression in participants with coexisting FM and migraine in comparison to those with migraine only [3], [5]. It is inconclusive if depression is triggered by FM or migraine, or if it is an independent provoking element for either if any. It has been shown that interconnections between anxiety, depression, and migraine may be linked to serotonin levels [24]. A subnormal concentration of serotonin may be involved in the dysregulation of "descending antinociceptive systems," contributing to FM and migraine [24], [25]. 


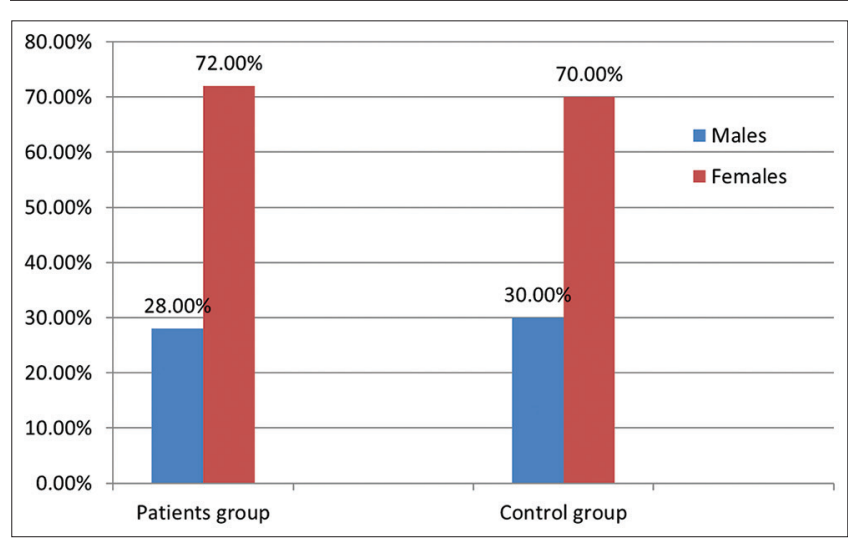

Figure 1: Gender distribution among patients and control groups

The primary drawback in the present study was the limited participants' number. We also did not look at the variations in FM frequency between chronic and episodic migraine patients. According to the findings of our study, it would be equitable to suggest screening for coexisting FM in the assessment and management of migraine patients.

\section{Conclusions}

Patients with migraines have a high percentage of FM. Migraine patients with concomitant FM had the tendency to be older, and most were female. FM was significantly more common in patients without aura. In comparison to patients without FM, individuals with FM and migraine experienced altered mood symptoms, had more intense and frequent headaches, and were more prone to have a critical headache-related impairment.

\section{Authors' Contributions}

The authors contributed equally to this study.

\section{References}

1. Cohen $\mathrm{H}$. Controversies and challenges in fibromyalgia: A review and a proposal. Ther Adv Musculoskelet Dis. 2017;9(5):115-27. http://doi.org/10.1177/1759720X17699199

PMid:28458723

2. Clauw DJ. Fibromyalgia: A clinical review. JAMA 2014;311(15):1547-55. http://doi.org/10.1001/jama.2014.3266 PMid:24737367

3. Ifergane G, Buskila D, Simiseshvely N, Zeev K, Cohen H. Prevalence of fibromyalgia syndrome in migraine patients. Cephalalgia. 2006;26(4):451-6. http://doi. org/10.1111/j.1468-2982.2005.01060.x

PMid: 16556247

4. Kucuksen S, Genc E, Yilmaz H, Salli A, Gezer IA, Karahan AY, et al. The prevalence of fibromyalgia and its relation with headache characteristics in episodic migraine. Clin Rheumatol. 2013;32(7):983-90. http://doi.org/10.1007/s10067-013-2218-2 PMid:23443337

5. Marcus DA, Bhowmick A. Fibromyalgia comorbidity in a community sample of adults with migraine. Clin Rheumatol. 2013;32(10):1553-6. http://doi.org/10.1007/s10067-013-2310-7 PMid:23743661

6. Whealy M, Nanda S, Vincent A, Mandrekar J, Cutrer FM Fibromyalgia in migraine: A retrospective cohort study. J Headache Pain. 2018;19(1):61. http://doi.org/10.1186/ s10194-018-0892-9

PMid:30066109

7. Fitzcharles $M$, Yunus $M$. The clinical concept of fibromyalgia as a changing paradigm in the past 20 years. Pain Res Treat. 2012;2012:184835. http://doi.org/10.1155/2012/184835 PMid:22135738

8. de Tommaso M. Prevalence, clinical features and potentia therapies for fibromyalgia in primary headaches. Expert Rev Neurother. 2012;12(3):287-95; quiz 296. http://doi.org/10.1586/ ern.11.190

PMid:22364327

9. Beyazal MS, Tüfekçi A, Kırbaş S, Topaloğlu MS. The impact of fibromyalgia on disability, anxiety, depression, sleep disturbance, and quality of life in patients with migraine. Noro Psikiyatr Ars. 2018;55(2):140-5. http://doi.org/10.5152/npa.2016.12691 PMid: 30057455

10. Headache classification committee of the internationa headache society. The international classification of headache disorders, $3^{\text {rd }}$ edition. Cephalalgia. 2018;38(1):1-211. http://doi. org/10.1177/0333102417738202

PMid:29368949

11. Wolfe F, Clauw DJ, Fitzcharles MA, Goldenberg DL, Häuser W, Katz RS, et al. Fibromyalgia criteria and severity scales for clinical and epidemiological studies: A modification of the ACR preliminary diagnostic criteria for fibromyalgia. J Rheumatol. 2011;38(6):1113-22. http://doi.org/10.3899/jrheum.100594 PMid:21285161

12. Rendas-Baum R, Yang M, Varon SF, Bloudek LM, DeGryse RE, Kosinski M. Validation of the headache impact test (HIT-6) in patients with chronic migraine. Health Qual Life Outcomes. 2014;12:117. http://doi.org/10.1186/s12955-014-0117-0 PMid:25080874

13. Stewart WF, Lipton RB, Dowson AJ, Sawyer J. Development and testing of the migraine disability assessment (MIDAS) questionnaire to assess headache-related disability. Neurology. 2001;56 Suppl 1:S20-8. http://doi.org/10.1212/wnl.56.suppl_1. s20

\section{PMid:11294956}

14. Kroenke K, Spitzer RL, Williams JB. The PHQ-9: Validity of a brie depression severity measure. J Gen Intern Med. 2001;16:606-13. http://doi.org/10.1046/j.1525-1497.2001.016009606.x PMid: 11556941

15. Shabbir $D$, Rajput $M$, Jan $D$. Cutaneous allodynia in migraine. Pak J Neurol Sci. 2020;15(1):5-8.

16. Vij B, Whipple MO, Tepper SJ, Mohabbat AB, Stillman M, Vincent $A$. Frequency of migraine headaches in patients with fibromyalgia. Headache. 2015;55(6):860-5. http://doi. org/10.1111/head.12590

PMid:25994041

17. Penn I, Chuang E, Chuang T, Lin CL, Kao CH. Bidirectional 


association between migraine and fibromyalgia:
Retrospective cohort analyses of two populations.
BMJ Open. 2019;9(4):e026581. http://doi.org/10.1136/
bmjopen-2018-026581
PMid:30962236

18. Assarzadegan F, Asgarzadeh S, Hatamabadi HR, Shahrami A, Tabatabaey A, Asgarzadeh M. Serum concentration of magnesium as an independent risk factor in migraine attacks: A matched case-control study and review of the literature. Int Clin Psychopharmacol. 2016;31(5):287-92. http://doi. org/10.1097/YIC.0000000000000130

PMid:27140442

19. Nappi RE, Sances G, Allais G, Terreno E, Benedetto C, Vaccaro $\mathrm{V}$, et al. Effects of an estrogen-free, desogestrelcontaining oral contraceptive in women with migraine with aura: A prospective diary-based pilot study. Contraception. 2011;83(3):223-8. http://doi.org/10.1016/j. contraception.2010.07.024 PMid:21310283

20. Aloisi AM, Butkevich I, Pieretti S. Gender differences in pain since birth. In: Neonatal Pain. Cham: Springer; 2017. p. 3-10.

21. Häuser W, Kühn-Becker $H$, von Wilmoswky $H$, Settan $M$, Brähler E, Petzke F. Demographic and clinical features of patients with fibromyalgia syndrome of different settings:
A gender comparison. Gend Med. 2011;8(2):116-25. http://doi. org/10.1016/j.genm.2011.03.002

PMid:21536230

22. de Tommaso M, Sardaro M, Serpino C, Costantini F, Vecchio E, Prudenzano MP, et al. Fibromyalgia comorbidity in primary headaches. Cephalalgia. 2009;9(4):453-64. http://doi. org/10.1111/j.1468-2982.2008.01754.x

PMid:19170692

23. Giamberardino MA, Affaitati G, Martelletti P, Tana C, Negro A, Lapenna D, et al. Impact of migraine on fibromyalgia symptoms. J Headache Pain. 2015;17:28. http://doi.org/10.1186/ s10194-016-0619-8

PMid:27002510

24. Deen M, Christensen CE, HougaardA, Hansen HD, Knudsen GM Ashina M. Serotonergic mechanisms in the migraine brain-a systematic review. Cephalalgia. 2017;37(3):251-64. http://doi. org/10.1177/0333102416640501

PMid:27013238

25. Becker S, Schweinhardt P. Dysfunctional neurotransmitter systems in fibromyalgia, their role in central stress circuitry and pharmacological actions on these systems. Pain Res Treat. 2012;2012:741746. http://doi.org/10.1155/2012/741746

PMid:22110944 